WellBeing International

WBI Studies Repository

$1-1999$

\title{
Alternatives to the Use of Animals in Higher Education
}

\author{
Jan van der Valk \\ Netherlands Centre Alternatives to Animal Use, \\ David Dewhurst \\ Leeds Metropolitan University \\ Ian Hughes \\ University of Leeds \\ Jeffrey Atkinson \\ Nancy University \\ Jonathan Balcombe \\ The Humane Society of the United States
}

See next page for additional authors

Follow this and additional works at: https://www.wellbeingintlstudiesrepository.org/acwp_he

Part of the Humane Education Commons, Politics and Social Change Commons, and the Social and Philosophical Foundations of Education Commons

\section{Recommended Citation}

van der Valk, Jan; Dewhurst, David; Hughes, lan; Atkinson, Jeffrey; Balcombe, Jonathan; Braum, Hans; Gabrielson, Karin; Gruber, Franz; Miles, Jeremy; Nab, Jan; Nardi, Jason; van Wilgenburg, Henk; Zinko, Ursula; and Zurlo, Joanne, "Alternatives to the Use of Animals in Higher Education" (1999). Education Collection. 45.

https://www.wellbeingintlstudiesrepository.org/acwp_he/45

This material is brought to you for free and open access by WellBeing International. It has been accepted for inclusion by an authorized administrator of the WBI Studies Repository. For more information, please contact wbisr-info@wellbeingintl.org.

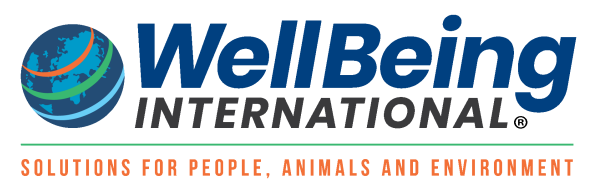




\section{Authors}

Jan van der Valk, David Dewhurst, lan Hughes, Jeffrey Atkinson, Jonathan Balcombe, Hans Braum, Karin Gabrielson, Franz Gruber, Jeremy Miles, Jan Nab, Jason Nardi, Henk van Wilgenburg, Ursula Zinko, and Joanne Zurlo 


\title{
Alternatives to the Use of Animals in Higher Education
}

\author{
The Report and Recommendations of ECVAM Workshop $33^{1,2}$
}

\author{
Jan van der Valk, ${ }^{3}$ David Dewhurst, ${ }^{4}$ Ian Hughes, ${ }^{5}$ Jeffrey Atkinson, ${ }^{6}$ \\ Jonathan Balcombe, ${ }^{7}$ Hans Braun, ${ }^{8}$ Karin Gabrielson, ${ }^{9}$ Franz Gruber, ${ }^{10}$ \\ Jeremy Miles, ${ }^{11}$ Jan Nab, ${ }^{12}$ Jason Nardi, ${ }^{13}$ Henk van Wilgenburg, ${ }^{14}$ Ursula \\ Zinko $^{15}$ and Joanne Zurlo
}

\begin{abstract}
${ }^{3}$ Netherlands Centre Alternatives to Animal Use, Yalelaan 17, 3584 CL Utrecht, The Netherlands; ${ }^{4}$ School of Health Sciences, Leeds Metropolitan University, Calverley Street, Leeds LS1 3HE, UK; ${ }^{5}$ Department of Pharmacology, University of Leeds, Leeds LS2 9JT, UK; ${ }^{6}$ Pharmacy Faculty, Nancy University, 5 rue Albert Lebrun, 54000 Nancy, France; ${ }^{7}$ Animal Research Issues, HSUS, 2100 L Street NW, 20037 Washington, DC, USA; ${ }^{8}$ Institute of Physiology, Deutschlandstrasse 2, 35033 Marburg, Germany; ${ }^{9}$ Swedish Fund for Research Without Animal Experiments, Gamla Huddingevagen 437, 12542 Alvsjo, Sweden; ${ }^{10}$ FFVFF, Biberlinstrasse 5, 8032 Zurich, Switzerland; ${ }^{11}$ Media Development Centre, University of Portsmouth, The Rotunda, Museum Road, Portsmouth PO1 2QQ, UK, ${ }^{12}$ IVLOS, Afdeling Onderwijszaken, PO Box 80127, 3508 TC Utrecht, The Netherlands, ${ }^{13}$ MOUSE, Borgo Allegri 27r, 50100 Firenze, Italy; ${ }^{14}$ Department of Pharmacology, AMC, Meibergdreef 15, 1105 AZ Amsterdam, The Netherlands; ${ }^{15}$ EuroNICHE, V. Myrbäck 108, 90588 Umea, Sweden; ${ }^{16}$ School of Hygiene and Public Health, Johns Hopkins University, Suite 840, 111 Market Place, Baltimore, MD 21202-2179, USA
\end{abstract}

\section{Preface}

This is the report of the thirty-third of a series of workshops organised by the European Centre for the Validation of Alternative Methods (ECVAM). ECVAM's main goal, as defined in 1993 by its Scientific Advisory Committee, is to promote the scientific and regulatory acceptance of alternative methods which are of importance to the biosciences and which reduce, refine or replace the use of laboratory animals. One of the first priorities set by ECVAM was the implementation of procedures which would enable it to become well-informed about the state-of-the-art of non-animal test development and validation, and the potential for the possible incorporation of alternative tests into regulatory procedures. It was decided that this would be best achieved by the organisation of ECVAM workshops on specific topics, at which small groups of invited experts would review the current status of various types of in vitro tests and their potential uses, and make recommendations about the best ways forward (1). In addition, other topics relevant to the Three Rs concept of alternatives to animal experiments have been considered in several ECVAM workshops.

The workshop on Alternatives to the Use of Animals in Higher Education was held at the Conference Centre of the Mediterranean

Address for correspondence: Jan van der Valk, Netherlands Centre Alternatives to Animal Use, Yalelaan 17, 3584 CL Utrecht, The Netherlands.

Address for reprints: ECVAM, TP 580, JRC Institute for Health \& Consumer Protection, 21020 Ispra (VA), Italy. ${ }^{1}$ ECVAM - European Centre for the Validation of Alternative Methods. ${ }^{2}$ This document represents the agreed report of the participants as individual scientists. 
Agronomic Institute of Chania, Crete, Greece, on 8-10 May 1998, under the chairmanship of Jan van der Valk (Netherlands Centre Alternatives to Animal Use [NCA], Utrecht, The Netherlands). It was organised by Jan van der Valk, David Dewhurst (Leeds Metropolitan University, UK) and Ian Hughes (University of Leeds, UK), as an initiative of the NCA Working Group on Education. Fifteen participants from eight countries attended the workshop, which was the first official meeting of experts involved in developing, using and evaluating animalfree models for educational purposes and promoting the use of these alternatives.

The overall aim of the workshop was to identify areas in which action should be taken to reduce the number of animals used in higher education. The issues reviewed and discussed included: a) the current use of animals in higher education; b) the range of alternatives currently available; c) the advantages and disadvantages of using alternatives in education; d) methods of disseminating information about alternatives to those involved in education systems, for example, students and academic teachers; and e) strategies for evaluating the educational effectiveness of alternatives.

All the data contained in this report refer to the European Union (EU) unless indicated otherwise.

\section{Introduction}

Higher education courses in the biomedical sciences typically use a variety of teaching and learning approaches, for example, lectures, seminars, tutorials, self-directed study and laboratory practical classes. In some subjects, for example, pharmacology, physiology and anatomy, many laboratory classes involve the use of animals and animal tissue. The objectives of such classes are often poorly defined, but may include: a) learning and practising laboratory skills, including generic skills, animal handling skills, and surgical/dissecting skills; b) acquiring new factual knowledge and reinforcing existing factual knowledge; c) learning and practising data-handling skills (taking measurements, recording, data presentation, analysis and interpretation skills); d) learning and practising oral and written communication skills; and e) developing responsible attitudes toward animal experimentation. Clearly, these objectives are important, and any alternative should fulfil these objectives at least as well as the traditional approach.

The number of animals used for educational purposes in Europe is small compared to the total number of animals used in research and testing, but it is significant, because several hundred thousand animals are used across the EU each year.

In article 25 of the European Convention for the Protection of Vertebrate Animals Used for Experimental and Other Scientific Purposes (2), the Council of Europe states that, "procedures carried out for the purpose of education, training or further training of professionals ... shall be restricted to those absolutely necessary for the purpose of the education or training concerned and shall be permitted only if their objective cannot be achieved by comparably effective audiovisual or any other suitable method." The use of animals in education has a major impact on the total use of animals in science, since animals are used to prepare students for research careers (3).

In this report, education is defined as the transfer of existing knowledge to improve the understanding of the anatomy, physiology and pharmacology of living systems. Training is defined as the learning and practising of skills.

Five separate groups have been identified, for whom education and/or training in animal use and alternatives are necessary, namely: animal technicians; scientists, including laboratory animal veterinarians; directors of animal facilities and animal welfare officers; national and regional inspectors; and members of ethics committees or institutional animal care and use committees (IACUCs; 4). This workshop report focuses mainly on the education and training of students in degree courses in biomedical sciences. As part of this education and training, animals are also used for dissection and to study anatomy, as sources of organs or tissues for physiological, pharmacological and surgical studies, for observation of animal behaviour, and to teach animal handling.

Students, animal welfare organisations, some teachers and others have frequently questioned the use of animals for the purposes mentioned above. The use of animals in teaching is often opposed on moral grounds and from an educational and practi- 
cal standpoint. Due to these considerations, more attention is now paid to approaches that reduce, refine or replace animal use in education.

The following groups of alternatives have been identified (5):

1. models, mannequins and mechanical simulators;

2. films and interactive videos;

3. computer simulations and virtual reality systems;

4. self-experimentation and human studies;

5. plant experiments;

6. observational and field studies;

7. waste materials from slaughterhouses and fisheries;

8. in vitro studies on cell lines;

9. dead animals from a humane and ethical source (for example, animals which have died naturally or which have been killed humanely after scientific procedures); and

10. clinical practise.

Many alternatives have been developed for educational purposes. However, their impact on animal use can only be determined when reliable data are available which report the numbers and species of animals being used, and the purpose of their use. This information would permit more-effective targeting of resources for developing alternatives where they will have the greatest impact.

In an earlier workshop, it was recommended that everyone involved in education and training, and especially lecturers and students, should have access to comprehensive information about alternatives (6). Ideally, this information should not only contain descriptions of the available alternatives, but also evidence of their educational benefits. Developers of alternatives should be encouraged to evaluate their models in order to provide objective information about them.

\section{The Current Status of the Use of Animals in Education}

Several countries publish data on animal use, although the amount of detail provided and the method of reporting varies widely (7). Currently, it is impossible to accurately determine how many animals are used in education in the EU. The overall picture that emerges from analysing the available data is that approximately $1 \%$ of animals used in science are used for education and training. This is considered to be an underestimate for several reasons. Registration procedures for providing information are not standardised, even within the EU. For example, the UK requires only the reporting of animals used for scientific procedures; the killing of an animal before use in teaching would not be registered (7). In some subjects, for example, pharmacology and anatomy, the majority of animals used would fall into this category and so reported numbers would be significantly smaller than the number of animals actually used. In addition, animals used in behavioural studies are not registered in national statistics, and not all vertebrates are registered. The data available from some EU countries are not up-to-date. In some countries, the most recent data are at least 6 years old.

From the data currently available, it appears that the main species being used in biomedical education are rodents, fish and amphibians. In general, institutions training laboratory technicians, and veterinary and biology students use the largest number of animals. Laboratory classes studying anatomy, physiology and pharmacology were identified as involving the most animals.

The European Commission (EC) has decided to take positive steps to make the number of vertebrate animals used for experimental purposes available (8), as stated in Directive 86/609/EEC articles 13 and 26 (9). Unfortunately, the EC will only require information on animals used in the procedures, and not the total numbers of animals used.

In order to define a policy to reduce or replace the use of animals in biomedical education, and to evaluate the effects of such a policy, reliable and comprehensive data on animal use are required. These data are also needed to determine whether the use of nonanimal alternatives has any impact on the numbers of animals used.

It is recommended that a standardised report form should be introduced by the EC, which records total animal use, including 
animals killed without prior procedures. Reporting should be annual.

\section{The Use of Alternatives in Education}

\section{Learning objectives}

It is important to distinguish between animal use where the primary purpose is teaching (for example, in laboratory classes) and where the primary purpose is research (for example, student research projects), where the concurrent teaching and learning are incidental. It is recognised that a substantial proportion of animal use, which results in teaching and learning, falls into this second category where students learn "on the job". It is difficult to see how restrictions can be imposed in this situation, other than those which control the research component, since the teaching is simply a spin-off and the animal use might have taken place even if students were absent.

Before animals are used in experiments which fall into the first category, i.e. where the primary purpose is teaching, tutors should be asked a number of key questions, as follows.

1. Are the teaching objectives of the experiment appropriate for this particular course?

2. Are the teaching objectives of the experiment appropriate for this particular group of students?

3. Are the teaching objectives of the experiment appropriate for all of the students in the group?

4. Is the use of animals the only way to achieve those teaching objectives?

5. Is the use of animals the "best" way to achieve those objectives?

It is questionable whether all tutors are sufficiently experienced and/or sufficiently unbiased to make a proper judgement on these questions. An independent body, at either a local or a national level, with carefully selected members, would be more appropriate. In most countries, an animal ethics committee or IACUC assesses animal use in research and education. In countries where this is not the case, similar bodies should be installed at a local or a national level.

\section{Learning objectives of classes in which animals are used}

The undergraduate curricula for a wide range of biological, medical and healthrelated courses in which physiology and pharmacology feature prominently, traditionally include laboratory experiments that reflect the practical nature of these subjects. These often involve the use of animals or animal tissue, sometimes unnecessarily.

The learning objectives of these classes can be summarised as (3):

1. teaching factual knowledge;

2. demonstrating the dynamic processes of life;

3. demonstrating the integration of complex systems;

4. teaching methods of scientific research;

5. developing problem-solving capabilities in the experimental environment;

6. stimulating independent working;

7. training in technical and manual skills; and

8. developing attitudes toward animal experimentation.

Animals used in teaching should not be regarded as dispensable tools. If students are regularly confronted with animal use during their studies, they might not be able to develop a balanced attitude toward the use of animals in research. Giving students the choice in the early stages of their study between using animals or animal-free learning methods to gain knowledge also helps them to develop an appropriate attitude toward the use of animals. Ideally, students should always be offered alternatives, and should be offered the opportunity to decide whether or not to attend an animal laboratory class. However, it is recognised that many students may be poorly equipped to make such a choice. Should students decide that the experience offered by an animal experiment is essential, they should be required to justify their decision. In all cases, students who will be confronted with animals during laboratory classes should at least have had ethical training to make them aware of issues surrounding the use of animals and the application of the Three Rs concept. 
One view is that the use of animals in education and training is only acceptable when: a) animals are observed in their natural setting or during brief periods of captivity; b) animals are obtained from an ethical source, for example, dissection of animals that have died naturally or those which have been humanely killed for other reasons; c) learning occurs in the clinical setting, where only animals in need of veterinary medical assistance are subjected to invasive procedures; or d) learning occurs by closely supervised apprenticeship in the research laboratory (specifically for students entering fields where they will need to use laboratory animals).

\section{Training}

Animal use for training purposes, particularly those experiments that involve suffering, should be delayed until a student decides to pursue a research career which involves animal experimentation (10). It may be obvious that non-animal models such as computer and audio-visual models are not able to teach or allow students to practice certain laboratory and surgical skills, and that when these skills are required in a future profession, non-animal alternatives might be unsuitable. Some training courses in laboratory animal science might be sufficient, in terms of knowledge and handling skills, for those going on to perform animal experiments in a future profession (11). In addition, such courses may foster a caring attitude to animals and promote a more critical approach to judging whether particular experimental protocols which involve animal use are really necessary, or how they might be refined to reduce numbers or suffering (12). In every situation, alternatives should be given full consideration.

\section{Advantages of alternatives}

Depending on the learning objectives, animal-free models have several advantages over animal experiments. In cases where students are not well-prepared for work with animals, the emotions aroused by being confronted with a dead or live animal might detract from the actual learning experience. Non-animal models can be developed in such a way as to achieve the learning objectives more effectively. For example:
1. a specific animal experiment might only be offered once, whereas an alternative model can often be used over and over again without constraints on time and place of study;

2. alternative models can offer unambiguous and complete data, and so can avoid the negative learning experience of an "unsuccessful experiment";

3. an alternative can have built-in selfassessment to allow students to gauge whether staged learning objectives have been achieved; and

4. alternatives which make use of modern audio-visual techniques offer the possibility of demonstrating phenomena that are normally unobservable in the equivalent animal experiment, such as animations of organ and cell functions and "flythroughs" of organ systems.

Although in some cases the development of an alternative model can be expensive, it can often be used repeatedly. Overall, the alternative model is cheaper than purchasing and caring for large groups of animals. The use of an alternative can also often save time for both the tutor and the students (13).

\section{Animal-free alternatives}

There are a wide range of animal-free models available for use in life sciences education today; all of them have strengths as well as limitations. The key to the successful integration of any alternative into a teaching and learning environment is the closeness of fit between the educational requirement, the context in which the alternative is to be used, and the choice of the medium (for example, computer or video).

The workshop participants identified various available formats in learning technology for the development of animal-free models, examined the strengths and weaknesses of each, and discussed the issues associated with the widespread implementation of alternatives from a technological perspective.

\section{Screen-based models}

When screen-based alternatives are being introduced in education, the governing factors are the learning objectives desired and the context in which they are to be achieved. 
The medium by which the material is delivered must be secondary to these considerations. If the introduction of screen-based alternatives is technology-led, there will be a greater risk of failure. However, technologyrelated issues such as desired functionality, mechanism of distribution to end-users, copyright and financial restriction must also be taken into account.

The oldest screen-based model, video, is an analogue medium, either on tape or on laser disc. VHS is ubiquitous and can still be very effective. The videodisc is now being replaced by digital video standards.

Computer-mediated alternatives can involve digital video, multimedia, computerassisted learning (CAL), simulations or selftesting models. These computer-mediated models can be either stand-alone versions, or distributed on local networks, or on the Internet. Often, site licences can be obtained for simultaneous use on multiple computers.

Trends are visible toward the use of multimedia and network distribution. Progress in learning technology influences the development of computer-mediated alternatives. The development of applications is often driven by the available technology, which sometimes offers new possibilities for alternatives in education (for example, computer simulations). On the other hand, some models are no longer available, because of hardware and software trends. It is also likely that inappropriate technology will be used if the learning objectives and context are not initially clearly identified.

Key factors in the development of computer-mediated alternatives are the use of the correct development tools, and collaboration. Several authoring tools exist for the production of CAL and multimedia, but the effective use of these tools requires specialised skills. Often the developer is the subject specialist, who also acts as programmer, instructional designer and graphic artist. It is preferable to have a team of professionals for the production of multimedia for educational purposes. Collaboration reduces duplication of effort, increases access to specialists, and raises the overall quality.

With the introduction of computer-mediated alternatives, the context of its use might also have to be adapted. The course or curriculum might need to be reorganised, or timetables changed. The correct and meaningful incorporation of CAL into a problem- based learning environment is of paramount importance.

\section{Human volunteers}

Human experimentation could, in some cases, be a good alternative in education. Human volunteers have many experimental possibilities, and for many study programmes (medicine, pharmacy and medical biology) are the ultimate model to study. In Marburg, Germany, two-thirds of all physiology experiments in education are performed by the students on each other.

Although human experiments have possibilities as alternatives for animal experimentation, they are not an option under some circumstances. In Leeds, UK, experiments on students in education are restricted by the fact that high insurance costs have to be paid. The faculty has full responsibility for the health of the students and the risks that they take.

\section{Three-dimensional models}

In addition to computer-mediated alternatives, several other learning alternatives could reduce, refine or replace animal experiments in education. Three-dimensional models, for example, can contribute significantly. In addition to the many plastic anatomy models now available for more than a dozen commonly dissected animal species and for the human body, there are also models and mannequins for more-specialised training. The rat and rabbit models developed by Koken, Tokyo, Japan, allow laboratory technicians and veterinary students to refine their skills in handling, dosing, drawing blood and intubation, before they use live animals (5).

\section{Demonstration of alternatives}

In many European countries, a great need exists for demonstration of the alternatives. This would assist groups who are trying to convince teachers in higher education. However, demonstrations are often limited, since they do not show the full range of functions of the real program. Plans exist for the production of a CD-ROM or a video with a compilation of different types of alternatives, to promote their use in education. In the UK, a resource centre has been set up for promoting CAL in the field of pharmacology. Demonstrations of alterna- 
tives on the Internet can be very effective, and there are several sites now available for this purpose.

Distribution also seems to be an important issue in the implementation of alternatives. Existing alternatives should be readily available for teachers all over Europe, but often this is not the case. Teachers who develop programs often organise their distribution themselves, which is usually inadequate as they lack the necessary facilities.

\section{Alternatives on view at the workshop}

Several alternatives were demonstrated during the workshop.

\section{Anatomy of the Rat}

The learning objectives of this linear video programme are to aid the identification and orientation of tissues and structures, to improve understanding of the functional relationship between organ systems within a mammal, and to improve dissection techniques. The target audience is high school pupils and first-year undergraduate students. It is currently being converted to a multimedia format, with the addition of sections to cover physiology and histology.

\section{Microlabs}

Microlabs consists of a series of computer programs in pharmacology education, developed with the support of grants from the EC and industry. This version can still be used on computers with a 286 processor, which is an advantage in Third World countries, where many animals are used for educational purposes. In addition, a Windows version of Microlabs is available. Distribution is free or on a collaborative basis. All programs are simulations without tutoring, so they can easily be changed and implemented in a specific learning situation.

The primary aim of Microlabs is to replace animal use in education by simulating the effects of drugs on isolated tissues in vitro and the effects on whole animals in vivo. Data obtained from the simulations can be analysed in a program for calculating quantitative structure-activity relationships. In this way, students become aware that many animal experiments can be excluded on theoretical grounds. The simulations can also be used for the design of experiments; variability in response, based on real experimental data, provides the opportunity to obtain skills for careful planning before beginning an experiment.

\section{Sciatic Nerve Tibialis Muscle Preparation}

This computer program simulates a pharmacological animal preparation for studying the action of drugs at the neuromuscular junction. There are no predefined experiments, which allows the teacher to decide how to apply it. The teacher has the freedom to study the effects of certain drugs, or to let students perform their own experiments. The user can set the dose, time and other parameters. The program can be used for many purposes, even for learning statistics. This program is one of a set of several simulations of pharmacological preparations and is now in use in 200 universities worldwide, for undergraduate and postgraduate students.

\section{Nerve Physiology}

The stimulus to develop this program was that a decision had to be made either to replace old physiological equipment, or to use a computer simulation. The program is a simulation of a practical experiment traditionally carried out on frogs. All aspects of the experiment can be studied with this program. It is not based on a mathematical model, but contains data from real experiments.

\section{Rat Blood Pressure}

Rat Blood Pressure presents data from a series of experiments designed to illustrate the action of drugs on the cardiovascular system (heart rate and blood pressure). The program provides extensive information about the experimental apparatus, the animal preparation and the protocol, and includes student exercises with feedback and selfassessment questions, for example, multiplechoice questions.

\section{Anaesthesia of Rats}

This CD-ROM includes a simulation of anaesthesia in the rat based on a mathematical model, but also contains a tutorial and some chapters on anaesthetic procedures. The CDROM teaches the student how to: determine the phase of anaesthesia by means of observation of the reflexes of the animal; identify the characteristics of the different classes of anaesthetic drugs; and apply procedures for anaesthesia by injection, inhalation, or a com- 
bination of both, and to distinguish factors influencing the effectiveness of anaesthesia. Moving video is an essential part of this CDROM. The first version was on video disc, but after several years of application in education, it was converted to CD-ROM. A publisher was involved in this development, and it will be interesting to see whether this commercial approach is successful in making alternatives widely available.

\section{SimMuscle}

This is one program in a series of five, which are distributed by Thieme Publishers. SimMuscle is an interactive CD-ROM, which focuses on the physiology of the striated muscle; all the virtual experiments are carried out on the leg muscle of a frog. The program includes video fragments and a natural interface. All the equipment required in a practical course is simulated, and students are expected to perform tasks similar to whose in the real experiment. The series of programs have been evaluated extensively with positive results.

\section{Problems Related to the Introduction of Alternatives}

Although alternatives are now widely available, the number of animals being used in education only seems to be decreasing slowly. The introduction and subsequent use of alternatives in education is not straightforward, for several reasons.

1. Some teachers are resistant to change and need to be convinced of the benefits of using alternatives.

2. The integration of an alternative into a course usually involves an initial investment of time and money.

3. Information about potential alternatives is not widely disseminated.

4. The quality of the material available varies considerably.

5. There may be financial, technical and other factors which restrict the use of alternatives (14).

\section{Attitudes of teachers}

Teachers with a positive attitude toward using alternatives to animal experiments, particularly those which they have developed themselves, know, in general, how to solve the problems outlined above. Other teachers resent being told what to do in the classroom by other scientists. Their attitude to replacing animal experiments is that they prefer the "traditional" way; they consider alternatives to be inferior, and the introduction of technology-based learning methods to be a retrograde step (15). Often, they are not interested in the ethics of using animals. Textbooks, laboratories and equipment are still oriented toward animal experimentation. Convincing these teachers of the advantages and ethics of using alternatives is difficult, the situation being very much polarised. Incorporating the principles of the Three Rs into teachers' initial training and post-qualification professional development would help to overcome some of these difficulties.

\section{Choice of medium}

Learning objectives and context should always be the guiding principles in the development of alternatives in education. From this, the appropriate choice of medium can more easily be determined.

Rapid changes in the technological infrastructure of higher education institutions (for example, the move from DOS to Windows NT in the space of only a few years) make it difficult to obtain the correct software. On the one hand, developers prefer to use new technologies to improve the presentational and interactive features of their computer programs. On the other hand, endusers are not always able to keep up with the pace of technological developments and might be unable to run the latest software. Therefore, financial restrictions on the introduction of alternatives are a problem, and funding for the development of alternatives is scarce. Being involved in these developments may even have negative consequences within a science career structure, which generally depends on excellence in basic research.

To overcome some of these problems, the EC should be encouraged to make funding available for the development, implementation and dissemination of alternatives. Furthermore, the essential collaboration of experts in the production of computer-mediated alternatives, and the mechanisms for the widespread distribution of alternatives, 
should be improved. Progress in technology (hardware and software) must be followed, but should not drive the development of alternatives.

\section{Curriculum issues}

Integrating alternatives into curricula may be difficult. The introduction of currently available material often means bringing new technologies into the classroom as educational tools. Simply replacing an animal experiment with a non-animal model is often not possible, since the new model may require a different level of support and the adoption of new learning styles. The application of these technologies can dramatically redefine the teacher-learner relationship and could have major consequences for the curriculum. Learning objectives should be redefined and the requirements for the learning environment, the system and the software, must be investigated. Failure to successfully introduce alternatives often results from software that does not meet the needs, hardware that does not properly fit into the training environment, and insufficient technical support.

\section{Resource centres}

If teachers are to be persuaded to use alternatives, their advantages must be demonstrated. In order to evaluate new materials, teachers must be provided with adequate information, including full descriptions of the alternative, the hardware requirements (if appropriate), independent reviews, details of cost and availability, and evidence of educational effectiveness. Information should be made available via electronic databases and Web sites, via discipline-based national and international scientific meetings, and via published articles about alternatives (see below).

One way of accomplishing this is via the establishment of a dedicated local or national centralised unit (resource centre), to provide a comprehensive electronic database of alternatives, and to collate examples of a wide range of alternatives which could be evaluated by students and teachers, either through visits to the centre, or by the centre's presence at appropriate disciplinebased scientific meetings.

The resource centre could also act as the coordinating centre for developing new alter- natives, for stimulating discussions on teaching objectives, for exchange of ideas and for providing advice on the implementation of alternatives.

\section{Information Sources on Alternatives}

Information about alternatives is disseminated in various ways, although to date there has been no concerted effort to unify the resources in one place. University teachers find out about alternatives from several sources, including: their own efforts in developing alternatives; other teachers; students who choose not to participate in animal experiments, and who themselves find alternative exercises; conferences and trade fairs; educational material marketing resources; databases, for example, NORINA, AVAR; outreach tours (for example, EuroNICHE) and publications; and computer program loan schemes from various institutions and organisations.

\section{Databases}

The most comprehensive current resource for alternatives in education is the NORINA database (16). This database is available through the Internet (http://oslovet.veths.no/norina/), and contains information about alternative models developed for classes from junior high school to university undergraduate level. The site contains a search engine for easy data retrieval.

AVAR (Association of Veterinarians for Animal Rights) provides the Alternatives in Education Database (Alt-Ed), which gives a short description of most models. The database is updated monthly and has a built-in search engine. It can be downloaded from the Internet at http://www.envirolink.org/arrs/ avar/alted db.htm.

The Biology Education Software Taskforce of the University of Washington has an Internet site where information can be found on biology education software (http://www.zoology.washington.edu/biosoft/). This site also contains reviews and comments. Although the comments are rather biased, they demonstrate the value of including more information on the models in current databases. It is important that these databases are regularly updated, provide uniform key word searches, and, 
preferably, can be accessed free of charge (6).

In addition to searchable electronic databases, some printed information is available. EuroNICHE has compiled an extensive overview of currently available alternatives, grouped by subject and medium used (5). The German Akademie für Tierschutz has established a bibliographic database on alternatives. Its printed version, the Gelbe Liste also contains information on alternatives in education (17).

Although most of the currently available information on alternatives in education is free, it appears that the future of these services is insecure, due to a lack of funding. It is therefore very important that the future of information providers should be secured.

\section{Improving information supply}

It is clear that, despite the currently available information resources, many teachers and students remain unaware of the existence of alternatives (18). Efforts should be focused on these groups to improve information flow. Activities that could be undertaken include:

1. linking with educational material marketing networks, for example, by working with textbook publishers who could advertise information on alternatives;

2. setting up a dedicated Web site or using an existing site such as Altweb (http://www.sph.jhu.edu/ altweb/) to present multimedia demonstrations of various alternatives;

3. using a dedicated Web site, other Web sites and e-mail list servers as a support mechanism for students who object to the harmful use of animals in the classroom;

4. establishing a standard or e-mail list to disseminate information to teachers and student organisations;

5. maintaining contact with various teachers' organisations and discipline-based societies, and making presentations at their national meetings to emphasise the educational value of methods that do not involve animals; and

6. developing guidelines for establishing an "alternatives committee" at universities, to review the use of animals in the class- room and to provide suggestions for suitable alternatives.

If established, the resource centre could carry out some of the activities mentioned above. Thus, the Centre could have a comprehensive loan system of alternatives like that of EuroNICHE (5) and the Humane Society of the United States (http:// www.hsus.org/alternat.html). Experience suggests that some lecturers are not inclined to make use of these facilities, and a better solution might be to take the centre to the teachers at discipline-based scientific meetings. A resource centre for pharmacology/physiology teaching materials, which carries out some of these activities, has been successfully established in the UK (as part of the pharma-CAL-ogy project: http://www.bphs.org.uk).

Furthermore, there is a need for demonstration materials related to existing alternatives to be made available in several countries. The production of a CD-ROM or video for promoting alternatives, preferably available in different languages, is necessary.

\section{Evaluating Alternatives}

Preferably, before any new model is advertised, reliable and standardised data on learning objectives, hardware requirements, costs and use should be available, although these may depend on how the alternative is employed. Like any other new model in science, the non-animal educational tool has to be evaluated. In particular, educational models need to be evaluated as a way of withstanding deep-rooted prejudices such as: the models do not meet educational objectives; students learn better when confronted with live or dead animals; non-animal models are too expensive; for some animal classes, such as dissection, there is no ethical problem; and introduction of such models would lead to loss of academic freedom.

Furthermore, a proper evaluation might yield data which could be used to improve the model. Format and media, content, level of interactivity, cost and time investment, and quality of teaching, are all criteria that need to be assessed during an evaluation. A carefully planned study will yield data which could lead to a better product and convince animal users of the educa- 
tional quality and potential benefits of alternatives.

One way to evaluate a non-animal model is to compare it with the animal model that it replaces. Criteria that should be taken into account include: whether the alternative can provide equivalent short-term and long-term learning gains; whether it meets the learning objectives; how much it costs to develop and implement the alternative; the time investment it demands of both staff and students; how user-friendly it is; and how available it is.

Several alternatives have been evaluated (13, 19-25). In general, students who used the non-animal models performed as well as those who used the animal model, or even better. One drawback of these evaluations was that only short-term learning gain was measured. Future studies should also attempt to measure the long-term learning prospects, though this may be very difficult to accomplish.

It might not be possible to validate each model individually, since both the animal model and the alternative are often not used in isolated classes, but as part of a course. The success of a practical class also depends on other factors, for example, the way it is being applied, whether it is for self-study or a tutored class, and the level of involvement of the tutor in introducing and summarising the findings (debriefing). Also, the attitude of the lecturer often determines the success of a practical class. When an alternative model is introduced with a lot of scepticism, the success rate of the model tends to be low, whereas if the lecturer is positive and enthusiastic, the chance of success is much greater.

When an alternative is already being used, lecturers and universities might have reservations about cooperating in the validation study, since they need to reintroduce the animal experiment to perform a proper comparison. In some countries, the law might even prohibit the performance of an animal experiment when an alternative model is available.

It is recommended that a group of experts with experience of evaluating alternatives should meet, possibly via another ECVAM workshop, to design a validation study for assessing the use of alternatives in higher education. This group should discuss the study protocol (what to measure and which evaluation tools to use), which universities and student groups should be involved, which alternatives should be validated, and what sources of funding might be available to support the study.

\section{Conclusions}

Current status of the use of animals in education

1. Official statistics from several countries in Europe suggest that approximately $1 \%$ of animals used in science are used for education and training. This is considered to be an underestimate, since there is no standardised data collection process and reporting procedure.

2. The trend seems to be toward fewer animals being used, although no hard data are available to support this contention.

3. Most of the animals used in higher education are rodents and amphibians, which are mainly used in undergraduate classes in pharmacology, physiology and anatomy.

The use of alternatives in education

4. A wide range of alternatives exist to reduce or replace the use of animals in higher education.

5. Teachers have an important role to play in defining the teaching and learning objectives of classes which use animals. They should be aware of potential alternatives and should be required to justify their continued use of animals.

6. Many alternatives have positive educational benefits and these should be promoted.

7. Several factors contribute to the limited use of currently available alternatives: lack of information about alternatives; lack of rigorous studies to evaluate alternatives; lack of time to introduce alternatives into the curriculum; resistance of teachers to change; and lack of multiple-language versions.

\section{Information sources on alternatives}

8. Several electronic and printed databases of alternatives exist, but the current 
impact of these on educational practice leaves much to be desired.

\section{Evaluating alternatives}

9. There have been relatively few studies in which the educational effectiveness of alternatives has been evaluated.

10. Most of these studies have demonstrated that alternative models can achieve many teaching and learning objectives. Some alternative models are more effective than animal models. However, few alternatives can be used to teach laboratory animal handling skills.

\section{Recommendations}

Current status of the use of animals in education

1. A standardised report form should be introduced by the EC. Total animal use should be recorded and reported annually.

\section{The use of alternatives in education}

2. The principles of the Three Rs should be incorporated into teachers' initial training and post-qualification professional development. This would help to overcome the factors that contribute to the rather limited use of the currently available alternatives.

3. The EC should make funding available for the development, implementation and dissemination of alternatives for use in education.

4. Where it is felt that the use of animals is indispensable to the learning objectives (for example, for the acquisition of practical skills), every effort should be made to reduce the numbers of animals used and to keep the potential for animal suffering to an absolute minimum.

5. Animal use for educational purposes should only be allowed after examination of the proposal and its approval by an ethical committee or via another appropriate independent review process. Ethics committees should include individuals with the competence to evaluate teaching methods that include animal use.
6. Students should have the right to use alternatives if animal experiments are not considered to be an essential part of their education. Students wishing to participate in exercises that use animals should be required to opt in, rather than the current opt out system for students wishing to use alternatives.

7. The EC should provide funding to support the establishment of a dedicated international and centralised unit (resource centre), to provide a comprehensive electronic database of alternatives and to hold examples of a wide range of alternatives. Teachers and students could evaluate the alternatives either through visits to the Centre or via the demonstration of the Centre at appropriate discipline-orientated scientific meetings. The Centre could also act as the coordinating centre for developing new alternatives, facilitating the development of different language versions, stimulating discussions on teaching objectives, exchanging ideas, and providing advice on the implementation of alternatives. Ideally, the Centre should be located at ECVAM.

\section{Information sources on alternatives}

8. Databases should contain more-comprehensive information, for example, description, contact details, availability, advice on use, target audience, and an independent evaluation of the material.

9. To reach professionals who have no affiliation with organisations dealing with alternatives, demonstrations should be encouraged at scientific meetings and at national meetings of science and biology teachers.

10. Resource centres, including the EC Centre, should be used to coordinate database information and to disseminate it more widely.

11. Professional journals should be encouraged to accept papers on new educational methods.

12. The future of some of the free information services on alternatives in education is insecure. The continuation of these 
services should be secured by the provision of the necessary funding.

\section{Evaluating alternatives}

13. A group of experts with experience in evaluating alternatives should meet via another ECVAM workshop, to design a European-wide validation study of the use of alternatives in higher education. This group would define an appropriate study protocol (what to measure, which evaluation tools to use), decide which universities and student groups should be involved, and which alternatives should be validated, and would suggest possible sources of funding.

\section{References}

1. Anon. (1994). ECVAM News \& Views. ATLA 22, $7-11$.

2. Council of Europe (1986). European Convention for the Protection of Vertebrate Animals Used for Experimental and Other Scientific Purposes, ETS No. 123. Web site http://www.coe.fr/eng/legaltxt/123e.htm. Strasbourg, France: Council of Europe.

3. Nab, J. (1990). Reduction of animal experiments in education in The Netherlands. ATLA 18, 57-63.

4. Balls, M., Goldberg, A.M., Fentem, J.H., Broadhead, C.L., Burch, R.L., Festing, M.F.W., Frazier, J.M., Hendriksen, C.F.M., Jennings, M., van der Kamp, M.D.O., Morton, D.B., Rowan, A.N., Russell, C., Russell, W.M.S., Spielmann, H., Stephens, M.L., Stokes, W.S., Straughan, D.W., Yager, J.D., Zurlo, J. \& van Zutphen, B.F.M. (1995). The Three Rs: the way forward. The report and recommendations of ECVAM workshop 11. ATLA 23, 838-866.

5. Zinko, U., Jukes, N. \& Gericke, C. (1997). From Guinea-pig to Computer Mouse: Alternative Methods for a Humane Education, 229 pp. Leicester, UK: EuroNICHE.

6. Janusch, A., van der Kamp, M.D.O., Bottrill, K., Grune, B., Anderson, D.C., Ekwall, B., Howald, M., Kolar, R., Kuiper, H.J.D., Larson, J., Loprieno, G., Sauer, U.G., Smith, A.J. \& van der Valk J.B.F. (1997). Current status and future developments of databases on alternative methods. The report and recommendations of ECVAM workshop 25. ATLA 25, 411-422.

7. Straughan, D.W. (1994). First European Commission report on the statistics of animal use. ATLA 24, 289-292.

8. EC (1998). Decision No. 2179/98/EC of the European Parliament and of the Council of 24 September 1998 on the review of the European Community programme of policy and action in relation to the environment and sustainable development "Towards Sustainability". Official Journal of the European Communities L275, $1-13$.

9. EC (1986). Council Directive of 24 November 1986 on the approximation of laws, regulations and administrative provisions of the Member States regarding the protection of animals used for experimental and other scientific purposes. Official Journal of the European Communities L358, 1-29.

10. Rowan, A.N. (1984). The use of animals in education: a failure to deal with contradictory values. In Of Mice, Models and Men: A Critical Evaluation of Animal Research (ed. A.N. Rowan), pp. 93-108. Albany, NY, USA: State University of New York Press.

11. van Zutphen, B.F.M. \& van der Valk, J.B.F. (1995). Education and training: a basis for the introduction of the Three Rs alternatives into animal research. ATLA 23, 123-127.

12. van Zutphen, B.F.M. (1991). Education and animal experimentation. In Replacement, Reduction and Refinement: Present Possibilities and Future Prospects (ed. C.F.M. Hendriksen \& H.B.W.M. Koëter), pp. 119-125. Amsterdam, The Netherlands: Elsevier.

13. Dewhurst, D. \& Jenkinson, L. (1995). The impact of computer-based alternatives on the use of animals in undergraduate teaching: a pilot study. ATLA 23, 521-530.

14. Balcombe, J.P. (1997). Alternatives in education: overcoming barriers to acceptance. In Animal Alternatives, Welfare and Ethics (ed. L.F.M. van Zutphen \& M. Balls), pp. 441-444. Amsterdam, The Netherlands: Elsevier

15. Balcombe, J.P. (1997). Student/teacher conflict regarding animal dissection. The American Biology Teacher 59, 22-25

16. Smith, A.J. \& Smith, K. (1997). The NORINA database of audiovisual alternatives. In Animal Alternatives, Welfare and Ethics (ed. L.F.M. van Zutphen \& M. Balls), pp. 511-515. Amsterdam, The Netherlands: Elsevier.

17. Rusche, B. \& Sauer U. (1994). A reviewed literature databank for alternatives to animal experiments - Gelbe Liste. In Alternatives to Animal Testing: New Ways in the Biomedical Sciences, Trends and Progress (ed. C. Reinhardt), pp. 85-88. Weinheim, Germany: VCH.

18. Uhl, R. \& Gruber, F.P. (1992). Ersatz von Ganztiermodellen in der biomedizinischen Ausbildung. In Tierschutz durch Alternativen; Ersatzund Ergänzungsmethoden zum Tierversuch (ed. Livaditis \& Vogt), pp. 286-290. Berlin, Germany: Verlag Gesundheit.

19. Dewhurst, D.G., Hardcastle, J., Hardcastle, P.T. \& Stuart, E. (1994). Comparison of a computer simulation program with a traditional laboratory practical class for teaching the principles of intestinal absorption. American Journal of Physiology - Advances in Physiology Education 267, S95-S103.

20. Leathard, H.L. \& Dewhurst, D.G. (1995). Comparison of the cost-effectiveness of a computer assisted learning program with a tutored demonstration to teach intestinal motility to medical students. Association for Learning Technology 3, 118-125.

21. Van Wilgenburg, H. (1997). Computer simulations in education. In Animal Alternatives, Welfare and Ethics ed. L.F.M. van Zutphen \& M. Balls), pp. 469-475. Amsterdam, The Netherlands: Elsevier.

22. Gruber, F.P. \& Spielmann, H. (1996). Der Myograph im Physiologie-Unterricht: praktische Vali- 
dierung in Deutschland. ALTEX 13, 190-194.

23. Lilienfeld, L. \& Broering, N. (1994). Computers as teachers: learning from animations. American Journal of Physiology - Advances in Physiology Education 267, S47-S54

24. Guy, J. \& Frisby, A. (1992). Using interactice videodiscs to teach gross anatomy to undergraduates at the Ohio State University. Academic Medates at the Ohio

25. Balcombe, J.P. (1996). Comparative Studies of Dissection and Other Animal Uses in Education, 2pp. Washington, DC, USA: HSUS. 